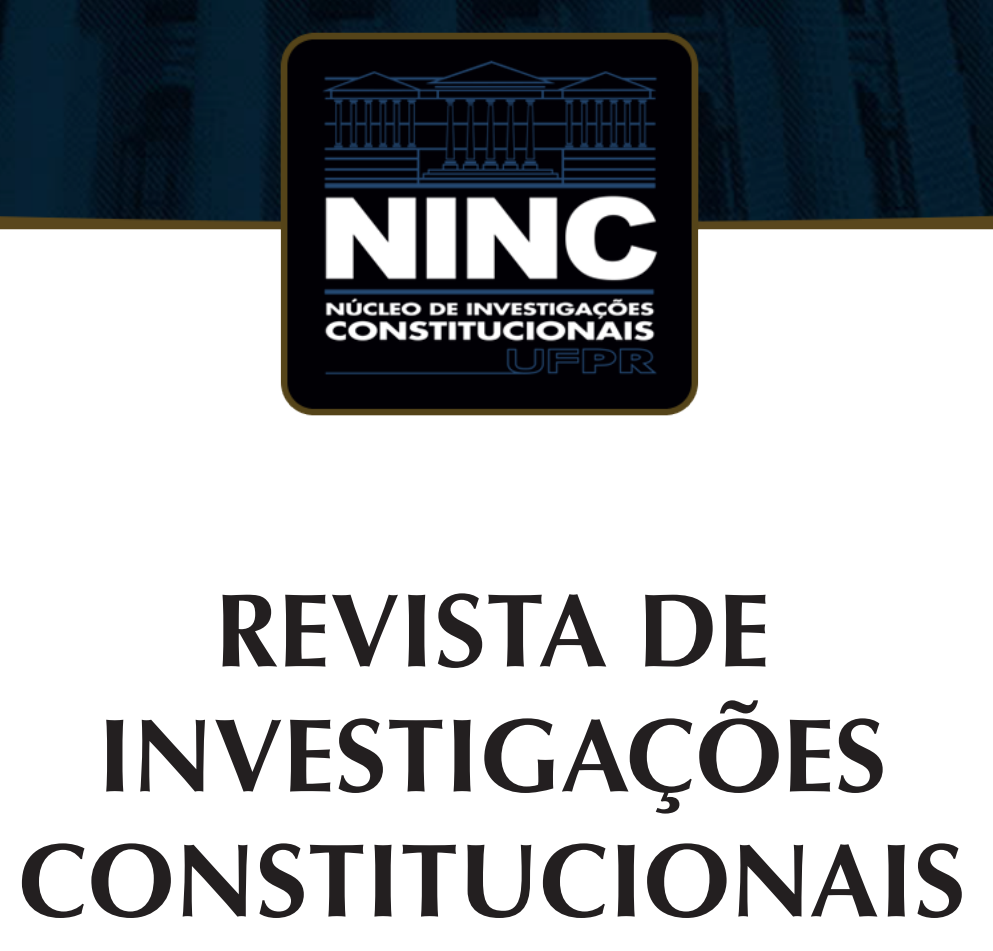

JOURNAL OF CONSTITUTIONAL RESEARCH

vol. 5 | n. 1 | janeiro/abril 2018 | ISSN 2359-5639 | Periodicidade quadrimestral Curitiba | Núcleo de Investigações Constitucionais da UFPR | www.ninc.com.br 


\section{Diálogos sanitários interinstitucionais e a experiência de implantação do NAT-JUS}

\section{Interinstitutional health dialogues and the NAT-JUS deployment experience}

\section{CYNARA MONTEIRO MARIANO*}

Universidade Federal do Ceará (Brasil) cynaramariano@gmail.com

\section{EMANUEL TEÓFILO FURTADO**}

Universidade Federal do Ceará (Brasil) etfurtado@uol.com.br

\section{FELIPE BRAGA ALBUQUERQUE***}

Universidade Federal do Ceará (Brasil) felipe_direito@hotmail.com

\section{FABRÍCIA HELENA LINHARES COELHO DA SILVA PEREIRA****}

Universidade Federal do Ceará (Brasil) abriciahc@gmail.com

Recebido/Received: 25.10.2017 / October 25th, 2017 Aprovado/Approved: 16.12.2017 / December 16th, 2017

\footnotetext{
Como citar esse artigo/How to cite this article: MARIANO, Cynara Monteiro; FURTADO, Emanuel Teófilo; ALBUQUERQUE, Felipe Braga; PEREIRA Fabrícia Helena Linhares Coelho da Silva. Diálogos Sanitários Interinstitucionais e a experiência de implantação do NAT-JUS. Revista de Investigações Constitucionais, Curitiba, vol. 5, n. 1, p. 169-188, jan./abr. 2018. DOI: 10.5380/rinc.v5i1.56027.

* Professora do Programa de Pós-Graduação em Direito da Universidade Federal do Ceará (Fortaleza, CE, Brasil). Doutora em Direito Constitucional pela Universidade de Fortaleza (Fortaleza, CE, Brasil). Pós-doutora em Direito Econômico pela Universidade de Coimbra. Mestre em Direito Público pela UFC. Diretora Acadêmica do Instituto Cearense de Direito Administrativo (ICDA) e Vice-presidente do Instituto Latino-americano de Estudos sobre Direito, Política e Democracia (ILAEDPD). E-mail: cynaramariano@gmail.com.

** Professor do Programa de Pós-Graduação em Direito da Universidade Federal do Ceará (Fortaleza, CE, Brasil). Doutor em Direito pela Universidade Federal de Pernambuco (Recife, PE, Brasil). Mestre em Direito Público pela UFC e Desembargador do Tribunal Regional do Trabalho da 7a Região.

*** Professor do Programa de Pós-Graduação em Direito da Universidade Federal do Ceará (Fortaleza, CE, Brasil). Doutor em Direito Constitucional pela Universidade de Fortaleza (Fortaleza, CE, Brasil). Pós-Doutorando em Saúde Pública pela Universidade Federal do Ceará. Mestre em Direito pela Universidade de Fortaleza. E-mail: felipe_direito@hotmail.com.

**** Mestranda do Programa de Pós-Graduação em Direito da Universidade Federal do Ceará (Fortaleza, CE, Brasil). Especialista em Direito Aplicado ao Ministério Público pela Escola Superior do Ministério Público da União, Técnica e Assessora do Ministério Público Federal no Ceará. E-mail: fabriciahc@gmail.com.
} 
Resumo

O presente trabalho tem como objetivo analisar o uso excessivo das prestações judiciais em matéria de efetivação do direito à saúde, inclusive os problemas decorrentes dele. Para tanto, utilizar-se-á de um estudo exploratório e descritivo, com base bibliográfica, documental, legislativa e jurisprudencial, com análise de obras de referência brasileira e internacionais, jurisprudência e legislação. Apontar-se-ão, na teoria e na prática, alternativas que visem ao mesmo fim de efetivar o direito fundamental à saúde, contudo que estejam atentas às limitações decorrentes da separação dos poderes. Apresentar-se-á então as teorias dos diálogos institucionais como ferramentas teóricas à disposição do Poder Judiciário para, reconhecendo suas limitações técnicas e institucionais, buscar junto aos poderes formuladores de políticas públicas soluções para concretizar direitos sociais sem que importe em ferir o equilíbrio na relação entre os poderes. Analisa-se ao final um exemplo prático que comprova a aplicabilidade das ideias levantadas na pesquisa: o caso da implantação dos Núcleos de Apoio Técnico ao Judiciário (NAT-JUS) que se promovem os diálogos interinstitucionais dentro do processo judicial.

Palavras-chave: diálogos interinstitucionais; direito à saúde; Núcleos de Apoio Técnico ao Judiciário; teorias dialogais; separação de poderes.

\section{Abstract}

This study has the goal of analyzing the excessive use of judicial provision when it comes to the realization of the right to health, including the problems arising from it. To do so, it will be used an exploratory and descriptive study, based on bibliographical, documentary, legislative and jurisprudential research, with analysis of Brazilian and international reference works, jurisprudence and the law. There will be presented, in theory and in practice, alternatives aimed at the same purpose of implementing the fundamental right to health, although they are sesitive to the limitations arising from the separation of powers. Therefore, there will be presented theories of institutional dialogues as theoretical tools for the Judiciary's willingness to recognize their technical and institutional limitations, together with the formulating powers of public policies, to find solutions to accomplish social rights without affecting the balance between the powers. At last, a practical example is verified, proving the applicability of the ideas raised in the research: the case regarding the implementation of Centers for Technical Support to the Judiciary (NAT-JUS), in which interinstitutional dialogues are promoted within the judicial process.

Keywords: interinstitutional dialogues; right to health; Centers for Technical Support to the Judiciary; dialogue theories; separation of powers.

\section{SUMÁRIO}

1. Introdução. 2. Direto à saúde no contexto da separação e dos diálogos entre poderes. 3. As escolhas em saúde e os diálogos institucionais. 4. Os diálogos no interior das decisões judiciais: a experiência do NAT - JUS. 5. Conclusões; 6 . Referências.

\section{INTRODUÇÃO}

Há pelo menos dois problemas que podem decorrer da análise pelo Poder Judiciário das demandas propostas quanto à efetivação do direito à saúde: formular políticas públicas de saúde, inclusive estabelecendo critérios de atendimento pelo sistema público de saúde, quando deveria exercer apenas um controle externo; e ainda ignorar o fator escolha política, econômica e social na formulação de uma política pública de saúde. Quando o judiciário formula políticas públicas, não está analisando orçamento e demais questões sociais. Mas não é razoável que se ignore sua colaboração no debate que envolve lesão ou ameaça ao direito à saúde. Os diálogos interinstitucionais podem ser uma forma de superar essa dicotomia entre a ilegitimidade da intervenção do Poder Judiciário na formulação ou na concretização de políticas públicas de saúde e o seu dever constitucional de atuar diante de lesão aos preceitos constitucionais que garantem 
a implementação de ações para prevenção, promoção e proteção à saúde. Seria uma terceira via, entre os argumentos para intervenção e não intervenção do Poder Judiciário em escolhas políticas.

Nesse contexto, cabe a ressalva de que o Poder Judiciário não pode olvidar o seu dever de autorrestrição em face da separação dos poderes. A efetivação e a concretização das políticas públicas são tarefas constitucionalmente dirigidas aos poderes políticos por excelência (legislativo e executivo), eis que os seus representantes são investidos de mandato conferido pelo povo para a realização dos objetivos constitucionais, em especial das decisões políticas fundamentais traduzidas pelo projeto constituinte de 1988, de implementação de um Estado de Bem Estar Social, que tem por escopo a ampliação da esfera dos direitos fundamentais clássicos à democratização econômica, cultural e social. Mesmo que o Estado de Bem Estar no Brasil sofra seus entraves diante do estado de exceção econômico ao qual toda a América latina está submetida, não se pode abandonar a perspectiva de que ele é constituinte do projeto de 1988, cuja defesa e até mesmo sua radicalização deve ser sempre buscada1.

O que se propõe, portanto, é identificar meios de compatibilizar a atuação do judiciário na concretização desse projeto constituinte com os demais princípios do Estado Democrático de Direito, sobretudo com a separação dos poderes.

Desse modo, serão abordados neste trabalho fatores importantes que corroboram com essa terceira via de participação judicial diante de falhas na prestação do serviço público de saúde. Inicialmente, propõe-se que a leitura em torno da separação dos poderes seja dinâmica, no sentido de permitir a colaboração entre eles, uma vez que o exercício das funções de um poder não pode superar as funções do outro, o que não impede posturas de contribuição entre eles. Portanto, a proteção ao direito à saúde pelo Poder Judiciário não pode ocorrer de modo a substituir as funções de gestão do sistema público de saúde do Poder Executivo, por exemplo. Contudo, quando acionado o judiciário por quem pretende ter uma medida de saúde implementada, deve-se buscar a colaboração contínua dos gestores públicos de saúde nessas demandas.

Ademais, no que se refere às atribuições do Poder Judiciário, temos que a necessária colaboração de outros poderes decorre do reconhecimento das limitações técnicas daquele, notadamente orçamentárias, médicas e de gestão, que, em geral, caracterizam as demandas que envolvem o direito à saúde, as quais buscam um provimento judicial sob o argumento da retórica constitucional e dos direitos. Desse modo, diante do excesso de provimentos jurisdicionais que impõem uma gestão de saúde pública voltada a atender a demandas de tal natureza, criando-se políticas públicas de forma inadequada por esse poder, é fundamental que se aprofundem os estudos e a

\footnotetext{
1 MARIANO, Cynara Monteiro; LIMA, Martonio Mont'Alverne Barreto; ALBUQUERQUE, Newton Menezes. Serviços públicos e radicalização do Estado Social: o lugar para uma perspectiva socialista nos dias atuais? In: MARIANO, Cynara Monteiro et all (Orgs.). Estado, Política e Direito Administrativo. Rio de Janeiro: Lumen Juris, 2017.
} 
análise de casos exitosos em que vias alternativas a essas distorções são implementadas e inauguram uma forma de superar a discussão acerca da possibilidade ou não de intervenção judicial nas demandas de saúde.

Para tanto, apresentar-se-á um mecanismo de auxílio mútuo entre os poderes ao exercerem seus papéis constitucionais, como desenvolvido pelos Núcleos de Apoio Técnico ao Judiciário (NAT-JUS), mais especificamente implementado pelo Tribunal de Justiça do Estado do Ceará, que, em pouco mais de cinco meses, já produziu 49 pareceres para instruir ações judiciais sobre medicamentos em curso nas Varas de Fazenda Pública da Justiça Estadual do Ceará.

\section{DIRETO À SAÚDE NO CONTEXTO DA SEPARAÇÃO E DOS DIÁLO- GOS ENTRE PODERES}

O Brasil adotou no plano normativo-constitucional, desde 1988, um modelo de proteção ao direito à saúde materializado em políticas sociais e econômicas que visem à redução do risco de doença e de outros agravos, estabelecendo que elas devem ser pautadas no acesso universal e igualitário às ações e serviços para sua promoção, proteção e recuperação da saúde. Assim, a própria Constituição Federal de 1988 firmou que a implementação dos direitos fundamentais nela previstos é o resultado esperado das políticas públicas. É nas políticas públicas que as disposições constitucionais relacionadas aos direitos sociais e econômicos são materializadas, sendo essa eficácia jurídica e social das disposições constitucionais a preocupação constitucional a partir de 1988,2 ou, em outras palavras, a eficácia dessas disposições é a verdadeira exigência de resultado que se faz na leitura do texto constitucional.

A efetivação dos direitos sociais e econômicos, contudo, decorre de escolhas não realizadas diretamente pelo legislador constituinte, mas por outros atores políticos. Telma Maria Gonçalves Menicucci relata que as definições políticas incentivam determinadas ações, mas bloqueiam outras, estabelecendo, desse modo, padrões de comportamento naquela sociedade alvo da política desenhada. São, portanto, nos dizeres da autora, as "regras do jogo" da alocação de recursos econômicos e políticos e da provisão de recursos e incentivos para atores políticos 3

Tradicionalmente, acredita-se que as grandes linhas das políticas públicas são definidas pelo Poder Legislativo, na forma de leis gerais e abstratas, as quais seriam executadas pelo Poder Executivo. Contudo, o Executivo também teria capacidade

\footnotetext{
2 HACHEM, Daniel Wunder. A maximização dos direitos fundamentais econômicos e sociais pela via administrativa e a promoção do desenvolvimento. Revista de Direitos Fundamentais e Democracia, Curitiba, v. 13, n. 13, p. 340-399, jan./jun. 2013. p. 348.

3 MENICUCCI, Telma Maria Gonçalves. Público e privado na política de assistência à saúde no Brasil: atores, processos e trajetória. Rio de Janeiro: Editora FIOCRUZ, 2007. p. 26.
} 
formadora de políticas públicas ${ }^{4}$, pois na atividade de realização concreta, "o próprio caráter diretivo do plano ou do programa [que encerrem as políticas públicas] implica a permanência de uma parcela da atividade 'formadora' do direito nas mãos do governo, Poder Executivo."5

Nesse passo, Celina Souza, analisando os escritos dos "pais fundadores da área de políticas públicas", como H. Laswell, H. Simon, C. Lindblom, D. Easton, entende que quando se concentra o foco das políticas públicas como papel dos governos, acaba-se por deixar de lado os aspectos conflituosos e os limites das decisões do governo, além das possibilidades de cooperação entre os governos e as instituições e grupos sociais ${ }^{6}$.

Assim, relevante é o papel das instituições jurídicas nessas definições, em essência, políticas. Interessante, portanto, que se observe que a eficácia dos direitos sociais depende da possibilidade de se cobrar uma ação concreta do Estado, o que, muitas vezes, somente pode ser realizado fora do campo de atuação de quem é responsável por definir regras de concretização desses direitos, ou seja, para além de um controle interno do poder que define as políticas públicas. Especificamente na área da tutela do direito à saúde, recentemente estão na mesa de decisões do Supremo Tribunal Federal e do Superior Tribunal de Justiça discussões que tratam de variados aspectos de sua realização, a saber: do fornecimento de medicamento pelo Estado fora das listas de dispensação do Sistema Único de Saúde (Recurso Especial n 1657156/RJ7); da obrigatoriedade ou não de o Estado fornecer medicamento não registrado na Agência Nacional de Vigilância Sanitária (repercussão geral no Recurso Extraordinário nº657718/MG); da obrigatoriedade de o Poder Público fornecer medicamento de alto custo para paciente que não possui condições financeiras para comprá-lo (repercussão geral no Recurso Extraordinário $\left.n^{\circ} 566471 / R N\right)^{8}$. Com a indicação de repercussão geral das matérias pelo STF e de afetação para efeitos repetitivos da matéria em apreciação pelo STJ, há evidentemente a expectativa de decisões judiciais desses Tribunais que estabeleçam critérios de julgamento para quase todas as demandas em que haja o pleito pelo fornecimento de medicamentos pelo SUS em curso no Brasil.

\footnotetext{
4 KRELL, Andreas J. Direitos sociais e controle judicial no Brasil e na Alemanha: os (des)caminhos de um direito constitucional comparado. Porto Alegre: Fabris, 2002. p. 99.

5 BUCCl, Maria Paula Dallari. As políticas públicas e o direito administrativo. Revista de informação legislativa. Brasília, v. 34 , n. 133, p. 89-98, jan./mar. 1997. p. 142.

6 SOUZA, Celina. Estado da arte da pesquisa em políticas públicas. In: HOCHMAN, G.; ARRETCHE, M.; MARQUES, E. (Orgs.). Políticas públicas no Brasil. Rio de Janeiro: Editora FIOCRUZ, 2007.p. 54

7 Foi determinada sua afetação para efeitos repetitivos, conforme decisão da Primeira Turma do STJ, com o seguinte tema afetado "Obrigação do Poder Público de fornecer medicamentos não incorporados, através de atos normativos, ao Sistema Único de Saúde", nos termos do voto do Relator Ministro Benedito Gonçalves, determinando-se, assim, a suspensão em todo território nacional dos processos pendentes, individuais e coletivos que versem sobre a questão. (https://ww2.stj.jus.br/processo/revista/ documento/mediado/?componente=ITA\&sequencial=1595643\&num_registro=201700256297\&data $=20170503 \&$ formato=PDF)

8 Pedidos de vista, em ambos, do Ministro Teoria Zavascki desde 28/09/16.
} 
As deliberações proferidas, ao final dos processos, formularão, inevitavelmente, políticas públicas. Isso porque fatalmente questões semelhantes serão levadas aos juízes e tribunais caso o paciente ou a família acredite estar dentro dos parâmetros sugeridos e aprovados pelo STF e STJ. Veja-se que, caso o STJ venha a entender, por exemplo, que o Estado deve fornecer medicamentos para além de suas listas de dispensação, formulando-se critérios para tanto (como da evidência científica, da hipossuficiência do paciente, do registro na ANVISA etc.), será feita pelo judiciário uma escolha política. Em regra, sem análise econômico-orçamentária ou social.

Heleno Taveira Torres destaca que uma vez que os recursos fiscais e patrimoniais do Estado são escassos, mas as demandas são sempre crescentes ao mesmo tempo em que a sociedade amplia suas complexidades, o que é acompanhado pela Fazenda Pública, é necessário que a escolha política da despesa pública atente à sua dupla função, não somente política, mas também social, a fim de garantir as demandas do Estado Social. Contudo, quando a Constituição não traça limites aos gastos públicos na consecução dos princípios do Estado Social, defende Torres que será sempre uma escolha do governante ou dos representantes legislativos, em uma contínua ponderação entre demandas sociais e situação conjuntural da economia. ${ }^{9}$

As escolhas democráticas não podem ir sempre ao judiciário, contudo. A autodeterminação legislativa sempre deve estar assegurada como a capacidade de agir de acordo com a vontade do povo, expressa no processo democrático. A interferência do judiciário no gasto público não é admissível prima facie, apenas o sendo quando se reclama uma valorização da decisão política do legislador e por conseguinte da democratização do gasto público, sendo cabível quando estiverem presentes indícios de vícios de ilegalidade ou de inconstitucionalidade ${ }^{10}$.

Nesse aspecto, como destacado por Christine Bateup, seria ideal que os julgamentos constitucionais fossem produzidos por meio de um processo de elaboração compartilhada entre o judiciário e os demais atores constitucionais ${ }^{11}$. Aos juízes não caberia, assim, interferir no processo democrático, mas garantir o funcionamento dos procedimentos de discussão democrática, bem como a proteção de minorias quando for necessário. No entanto, os magistrados não devem olvidar que o Estado Democrático de Direito brasileiro está comprometido com a realização da justiça social, comandando como objetivos a redistribuição de rendas e a concretização de um Estado de

\footnotetext{
9. TORRES, Heleno Taveira. Direito constitucional financeiro. São Paulo: Thomson Reuters; Revista dos Tribunais, 2014. p. $139,141$.

10 TORRES, Heleno Taveira. Direito constitucional financeiro. São Paulo: Thomson Reuters; Revista dos Tribunais, 2014 , p. 145-146.

11 BATEUP, Christine. The dialogic promise: assessing the normative potential of theories of constitutional dialogue. New York: New York University School of Law, 2005. p. 1.
} 
Bem Estar Social - previsto no preâmbulo, no art. 193, art. 23 §único, art. 219, art. 230, art. 186 , art. $231, \S 1^{\circ}$, da CF/8812.

É sob essa perspectiva de que a política e a força da democracia não sejam substituídas pela expectativa da decisão judicial 13 que se espera do Poder Judiciário formas de compatibilizar os novos desafios de efetivação do Estado de Bem Estar Social, que diuturnamente se apresentam aos juízes nas demandas que envolvem, especialmente, o direito à saúde. No contexto em que não pode o judiciário escolher beneficiários em detrimento dos demais, com quebras de isonomia, acabam por trazer um prejuízo a uma gama de pessoas que estão longe do acesso aos juízes e Tribunais. As maiores injustiças podem decorrer daí e estarem ainda ocultas ${ }^{14}$, ignorando a realidade daqueles que em virtude do alto custo, da morosidade e das dificuldades, inclusive geográficas, não conseguem ter acesso ao Judiciário. Contudo, existem posições contrárias, como é sabido, corroboradas em especial por aqueles que vivenciam a prática da atividade jurisdicional e, muitas vezes, em um espírito de justiça e humanidade, não podem prosseguir na linha de omissão do Poder Público diante de um direito fundamental não promovido. Para esses, a realização de concurso público aliada a uma atuação em conformidade com o regime constitucional, desde a fundamentação com base no regime jurídico constitucional até os mecanismos de controle e recursos, asseguram a legitimidade dos magistrados em termos democráticos, não sendo essa entregue apenas a quem a obteve por escolha popular ${ }^{15}$.

Independente do acerto ou da extrapolação nas atribuições desses atores jurídicos, o que vem se colocando é que efetivar direitos atrelados à dignidade da pessoa humana, quando o Estado (Poder Público de forma geral) não os garante de forma satisfatória, pode passar pela atuação externa daqueles que originariamente não deveriam criar políticas públicas. Não vemos isso de forma negativa. Ao contrário, na tutela de direito metaindividual (difusos e individuais homogêneos), esse controle externo, feito no Judiciário (com a participação dialogal dos outros poderes), pode ser uma forma de contribuição na formulação da política pública.

Nesse rumo, a via judicial passou a ser inclusive incorporada como "instrumento à disposição dos cidadãos para a luta em prol da inclusão social e da garantia da vida digna"16. Firmando-se a importância desse controle externo judicial como contribuição

\footnotetext{
12 TORRES, Heleno Taveira. Direito constitucional financeiro. São Paulo: Thomson Reuters; Revista dos Tribunais, 2014. p. 147.

13 TORRES, Heleno Taveira. Direito constitucional financeiro. São Paulo: Thomson Reuters; Revista dos Tribunais, 2014 . p. 153.

14 TORRES, Heleno Taveira. Direito constitucional financeiro. São Paulo: Thomson Reuters; Revista dos Tribunais, 2014 . p. 158.

15 MATIAS, João Luis Nogueira; MUNIZ, Águeda. O poder judiciário e a efetivação do direito à saúde. Revista Brasileira de Políticas Públicas, Brasília, v. 5, n. 1, p. 194-206, p. 199-200, 2015.

16 SARMENTO, Daniel. Por um constitucionalismo Inclusivo: História Constitucional Brasileira, Teoria da Constituição e Direitos Fundamentais. Rio de Janeiro: Lume Juris, 2010. p. 181.
} 
para realização dos objetivos constitucionais, surge então a necessidade de identificar até que ponto essa contribuição não poderia violar as atribuições de cada instituição.

Dieter Grimm comenta que se por um lado uma política totalmente juridicizada (no sentido de estar subordinada ao direito) perderia seu caráter político, as Constituições podem fixar condições para decisões políticas, não se lhes sendo possível, entretanto, normatizar o que conduz o processo decisório, como convicções, interesses, problemas e iniciativas, os quais somente a partir de certo ponto podem ser analisados pelo direito. ${ }^{17}$ Nesse aspecto da relação limitada entre os sistemas político e jurídico, Marcelo Neves concebe a Constituição como acoplamento estrutural entre direito e política, ou seja, nesta concepção, a Constituição é um mecanismo de interpenetração e interferência entre os sistemas sociais jurídico e político, pressupondo-se, para essa construção, uma autonomia operacional dos dois sistemas ${ }^{18}$.

Atento aos fatores que impedem uma sobreposição entre Direito e Política, e com escólio nas lições de Juarez Freitas, Emerson Gabardo aponta o necessário olhar ampliado que se deve ter sobre a questão de interferências do judiciário no campo político, com cautelas preservadas, não se podendo, entretanto, voltar a Montesquieu e corroborar com um judiciário nulo, inclusive com base na Constituição que determina que nada pode ser subtraído de sua apreciação 19. Desse modo, o princípio da separação dos poderes ou o ideal de cumprir a autonomia dos sistemas político e jurídico não podem impor uma barreira absoluta à revisão judicial quanto à alocação de recursos realizada pelo Estado, embora pressupunham respeito às decisões tomadas pelos órgãos representativos. Assim, é necessário se buscar critérios para a atuação do Poder Judiciário na realização de atos que interfiram em decisões tomadas pelas instituições políticas a fim de garantir tanto a separação dos poderes, quanto a força dos direitos fundamentais assegurados na Constituição Federal.

Uma alternativa para que as instituições judiciais executem certo controle externo de políticas públicas e colaborem para sua formulação é a realização de diálogos com os demais centros de decisão, especialmente daqueles que criam e efetivam essas políticas, sendo desaconselhado que haja um isolamento por quem realizará esse controle externo daqueles que tem legitimidade para prever e executar políticas públicas e vice-versa.

\footnotetext{
17 GRIMM, Dieter. Constituição e Política. Tradução Geraldo de Carvalho. Belo Horizonte: Del Rey, 2006. p. 10-11.

18 NEVES, Marcelo. A Constitucionalização Simbólica. São Paulo: WMF Martins Fontes, 2007. p. 148.

19 FREITAS, Juarez. O controle dos atos administrativos e os princípios fundamentais, 1997. p. 84 apud GABARDO, Emerson. Princípio Constitucional da Eficiência Administrativa. São Paulo: Dialética, 2002. p. 135-13
} 


\section{AS ESCOLHAS EM SAÚDE E OS DIÁLOGOS INSTITUCIONAIS}

Diante da já focada necessária colaboração entre os poderes, mesmo que a efetivação de direitos sociais seja requerida ao Poder Judiciário, inevitável que esse poder note que a formulação de escolhas e políticas públicas devem ser realizadas, primordialmente, em outros poderes. Ademais, é ainda importante perceber até que ponto pode o indivíduo esperar que uma dessas escolhas contemplem suas necessidades de promoção, proteção e recuperação da saúde. A fim de não se incorrer no erro de ver as demandas relacionadas ao direito à saúde analisadas sobre uma perspectiva de prestações irrestritas, valemo-nos da observação de Andreas J. Krell ao comentar que a decisão do Tribunal Constitucional Federal Alemão, que trouxe à tona a tese da reserva do financeiramente possível, deixando claro que os direitos a prestações positivas estão relacionados àquilo que o indivíduo de forma racional pode esperar da sociedade, apontando que essa teoria impossibilita exigências acima de um "certo limite básico social"20.

Por outro lado, o mesmo autor advoga a tese que, com base na Constituição de 1988, deve-se tratar os problemas de saúde de todos. Quando o volume de recursos não for suficiente para tanto, deve-se retirar recursos de áreas não intimamente relacionadas com direitos essenciais ao homem. De modo que qualquer alegação de falta de recursos para direitos mais essenciais à condição humana , como vida e saúde, devam ser plenamente justificados pelo Estado caso os negue21.

Portanto, ainda que se reconheça que uma política pública envolve uma escoIha econômica e política, ela não pode servir de justificativa para a não realização de direitos mais essenciais. A análise daquilo que o indivíduo pode esperar da sociedade no campo do direito à saúde interessa aos atores jurídicos diante da negação de um tratamento de saúde por parte dos atores políticos. Parece-nos que não é razoável exigir de uma sociedade com sérios problemas sociais tratamentos de saúde caros, experimentais e não acessíveis a todos os usuários do sistema público. Contudo, é razoável que o indivíduo espere da sociedade o fornecimento de um medicamento para combater uma neoplasia maligna, cuja política estabelecida não contempla o fornecimento de medicamento mas o repasse de valores, por vezes, inviáveis para se realizar o tratamento, ou ainda um procedimento cirúrgico, fornecido em tese pelo SUS, mas que por ele se aguarda em lista de espera há tantos anos.

É importante perceber que quando há um desentendimento acerca do significado de direitos, Christine Bateup defende que a combinação de entendimentos oferece a melhor chance de se produzir respostas às questões constitucionais, não apenas

\footnotetext{
20 KRELL, Andreas J. Direitos sociais e controle judicial no Brasil e na Alemanha: os (des)caminhos de um direito constitucional comparado. Porto Alegre: Fabris, 2002. p. 52.

21 KRELL, Andreas J. Direitos sociais e controle judicial no Brasil e na Alemanha: os (des)caminhos de um direito constitucional comparado. Porto Alegre: Fabris, 2002. p. 53.
} 
para solucionar casos individuais, mas também para as pessoas como um todo. $22 \mathrm{Se}$ esse aspecto não for observado, e a repartição de recursos e incentivos nas ações governamentais for desigual, serão formados grupos favorecidos com as políticas que trabalharão para fornecer obstáculos a alterações institucionais posteriores e/ou a alterações de políticas já existentes, de tal forma que os desenhos de políticas públicas alteram os processos políticos e modelam identidades de grupo 23 .

Embora se reconheça que a forma como as políticas públicas de saúde se desenham influencia o modo como as instituições (políticas e jurídicas) pautarão sua atuação, visualiza-se que atualmente vem surgindo uma necessidade de identificar uma confluência de interesses entre quem define essas regras do jogo das prioridades coletivas esboçadas em políticas públicas e quem as fiscaliza ou executa, exatamente para evitar as distorções que atuações polarizadas podem gerar. Parece-nos que não há mais espaço para o isolamento de quem idealiza o jogo diante daqueles que efetivamente colocam as regras desse jogo em prática. Desse modo, é necessária a realização de pesquisas capazes de trazer alternativas para que as decisões judiciais funcionem não como um mecanismo de Hobin-Hood às avessas, as quais geram efeitos reflexos que mais contribuam para a irracionalidade do sistema, sem que se esclareçam os limites e possibilidades econômicas da implementação delas 24 .

Nessa mesma tônica, tramita na Câmara dos Deputados o Projeto de Lei no 8.058/2014, que estabelece um procedimento processual especial para o controle e intervenção em políticas públicas pelo Poder Judiciário. O rito, informa o Projeto de Lei, terá como características a facilitação do diálogo institucional entre os poderes, a abertura ao diálogo entre o juiz, as partes, os representantes dos demais poderes e a sociedade e o reconhecimento da tendência às soluções consensuais, construídas e executadas de comum acordo entre os poderes.

Além das já destacadas questões econômicas que envolvem demandas de saúde, a grande utilidade de se discutir políticas públicas no âmbito de instituições para além dos Poderes Executivo ou Legislativo, inserindo nesse circuito de discussões muitas vezes os atores jurídicos, está no fator de pluralidade social que ampara e constitui as ações de saúde. Lucíola Santos Rabello analisa o campo da saúde pública sob uma perspectiva sociológica e diz"nenhum conceito ligado à promoção da saúde é consensual, objetivo, o que implica não se poder isolar ou colocar o fiel da balança na comunidade ou nas instituições."25

\footnotetext{
22 BATEUP, Christine. The dialogic promise: assessing the normative potential of theories of constitutional dialogue. New York: New York University School of Law, 2005. p. 78.

23 MENICUCCI, Telma Maria Gonçalves. Público e privado na política de assistência à saúde no Brasil: atores, processos e trajetória. Rio de Janeiro: Editora FIOCRUZ, 2007. p. 26-27.

24 SOUZA, Jorge Munhós de. Diálogo institucional e direito à saúde. Salvador: JusPodvim; 2013. p. 309.

25 RABELLO, Lucíola Santos. Promoção da saúde: a construção social de um conceito em perspectiva do SUS. Rio de Janeiro: Editora FIOCRUZ, 2010. p. 18.
} 
O especial diálogo entre as esferas políticas e jurídicas envolvidas na prestação dos direitos sociais é fundamental para que o sistema de execução e controle de políticas públicas pelos atores jurídicos funcione adequadamente e para que a contribuição dada por eles seja efetiva. Nesse contexto, interessante pontuar ideias que acabam por ganhar força nesse debate como as teorias dialógicas, a exemplo do chamado "controle fraco" dos direitos sociais pelos tribunais, da obra "Weak Courts, Strong Rights" do jurista norte-americano Mark Tushnet. O modelo de weak courts foi reformulado no final do século XX, em substituição ao modelo de strong courtes em que as decisões das Cortes vinculam os outros ramos a médio e longo prazo 26

A reciprocidade na influência das soluções encontradas marca essa nova visão, não no prestígio absoluto de um poder sobre o outro, tampouco a weak form review representa uma revisão judicial limitada27. Para essa doutrina do "Weak Courts, Strong Rights", um controle fraco de políticas públicas concretizadoras de direitos sociais seria representado por uma atuação do judiciário que não impediria a superação de suas decisões em processos políticos, ou seja, as decisões dos tribunais poderiam passar por um diálogo com os poderes com representantes eleitos, ao contrário do controle forte, caracterizado pela imutabilidade e vinculação das decisões do Poder Judiciário, feitas sem participação política alguma. Essa postura dialogal, característica do controle fraco, advogada por Mark Tushnet 28 , pode embasar uma mudança na natureza do processo judicial no que se refere aos direitos sociais.

Ressalta Daniel Sarmento que o processo judicial foi inicialmente desenhado para solucionar questões bilaterais da justiça comutativa, em que os interesses em disputa são apenas aqueles das partes. No entanto, quando se refere a temas envolvendo direitos sociais, tem-se presente sobretudo questões de justiça distributiva, de natureza multilateral, tendo em vista a necessidade de se considerar que garantir prestações a alguns significa retirar recursos do bolo que serve aos demais. Outrossim, se pensarmos que aqueles que recebem prestações judiciais em detrimento dos demais são os que possuem mais condições de acesso ao judiciário, inclusive decorrente de carência de informações, as consequências de decisões judiciais que não se debruçam sobre o "bolo que serve aos demais" são ainda mais prejudiciais ao sistema de saúde como um todo 29 .

Não se pode, portanto, olhar para a repartição dessas prestações dos sistemas de saúde no momento atual e fugir do diálogo que traga "elementos fáticos e critérios

\footnotetext{
26 TUSHNET, Mark. Alternative Forms of Judicial Review. Michigan Law Review, Ann Arbor, vol. 101, n. 8, aug. 2003. p. 27812784.

27 TUSHNET, Mark. Alternative Forms of Judicial Review. Michigan Law Review, Ann Arbor, vol. 101, n. 8, aug. 2003. p. 2786.

28 SARMENTO, Daniel. Por um constitucionalismo Inclusivo: História Constitucional Brasileira, Teoria da Constituição e Direitos Fundamentais. Rio de Janeiro: Lume Juris, 2010. p. 186.

29 SARMENTO, Daniel. Por um constitucionalismo Inclusivo: História Constitucional Brasileira, Teoria da Constituição e Direitos Fundamentais. Rio de Janeiro: Lume Juris, 2010. p. 210.
} 
de decisão, racionalidades próprias e tantos outros que interferem no processo de escolha"30 Acredita-se que essa escolha política, econômica e social encerrada em uma política pública de saúde pode ser construída pelas instituições estatais partindo do pressuposto que os interesses não são opostos, mas confluentes. Uma atuação articulada, assim, das instituições estatais políticas e judiciais melhor reflete essa tônica do diálogo.

Jorge Munhós de Souza destaca que a ideia de que uma normatividade constitucional, quando não implementada, poderia gerar um controle judicial com base nas garantias previstas no art. $5^{\circ}$ da CF/88, inicialmente não teve recepção nos Tribunais brasileiros no que tange aos direitos sociais, com base inclusive na retórica dessas normas terem natureza programática, da impossibilidade de romper com a separação dos poderes e ainda da discricionariedade administrativa31. Posteriormente, em uma tendência neoconstitucional de interpretação, passaram os Tribunais a identificarem suas funções de efetivação do projeto constitucional e experimentaram o lado oposto da questão: ser protagonistas de um processo de judicialização e expansão constitucional, passando, assim, "da desimportância ao apogeu" do Judiciário pelas questões que envolviam direitos sociais 32 .

Superada essa segunda fase - de apogeu ou supremacia judicial, identificaramse problemas em uma atuação de última palavra do Poder Judiciário na efetivação do direito à saúde. Ver os efeitos sistêmicos que dificultam a racionalização do sistema público de saúde 33 foi um sintoma importante da evolução da discussão e do posicionamento judicial quanto a essa questão. Munhós de Souza pondera que mesmo nos Estados Unidos, onde se desenvolveu o modelo paradigmático de supremacia judicial desde a decisão do juiz Marshall em 1803, a melhor doutrina sobre modelos institucionais foi lá produzida, revelando-se, assim, que não há uma relação indispensável entre o modelo institucional adotado e o uso das teorias dialogais, podendo essas serem usadas em maior medida a depender do uso pelos juízes de um controle fraco, embora o modelo seja de supremacia judicial. Ou ainda que o modelo seja de supremacia do legislativo, os juízes podem usar um modelo de controle forte e fazerem menos uso das teorias dialogais34. As teorias podem ser utilizadas em graus diversos, como expressão de diálogos no interior das decisões judiciais, quando terão certa força prescritivas, de dever-ser, ou ainda como fator de interação entre os ramos da soberania popular,

\footnotetext{
30 VALLE, Vanice Regina Lírio do. Diálogo institucional com pressuposto da efetividade constitucional. A\&C. Revista de Direito Administrativo e Constitucional, Belo Horizonte, n. 23, ano 6, jan./mar. p. 189-206, jan./mar. 2006. Da mesma autora: VALLE, Vanice Regina Lírio do. Dialogical constitutionalism manifestations in the Brazilian judicial review. Revista de Investigações Constitucionais, Curitiba, vol. 1, n. 3, p. 59-90, set./dez. 2014.

31 SOUZA, Jorge Munhós de. Diálogo institucional e direito à saúde. Salvador: JusPodvim; 2013. p. 25.

32 SOUZA, Jorge Munhós de. Diálogo institucional e direito à saúde. Salvador: JusPodvim; 2013. p. 28.

33 SOUZA, Jorge Munhós de. Diálogo institucional e direito à saúde. Salvador: JusPodvim; 2013. p. 31.

34 SOUZA, Jorge Munhós de. Diálogo institucional e direito à saúde. Salvador: JusPodvim; 2013. p. 69-71.
} 
quando terão efeitos descritivos a serem utilizados no contexto da separação de poderes $^{35}$. No Brasil, parece ter sido adotado um modelo moderadamente dialógico, sendo um exemplo de sistema de controle judicial forte (supremacia judicial) com adoção de formas fracas de controle judicial, segundo apontado por Jorge Munhós de Souza, utilizando-se da classificação de Mark Tushnet ${ }^{36}$.

Importante anotar que o Judiciário, embora consagrado como o detentor da palavra última de conflitos entre particulares, o mesmo não pode se dizer quando diante de questões constitucionais. Munhós de Souza destaca também que, a despeito de a Constituição brasileira indicar o STF como tendo a função precípua de sua própria guarda, há casos em que o legislativo ainda pode fazer determinadas opções, mesmo diante da discordância do STF. Se o modelo adotado no Brasil permite que haja um controle judicial mais fraco, aumentando-se o equilíbrio de forças entre o Poder Judiciário com as demais instituições de atribuição de significado e sentido à Constituição, "a disseminação de uma cultura mais dialógica certamente pode contribuir para a sedimentação entre nós de um sistema mais interativo e menos judicialista"37. Se assim for, sedimentada a ideia de diálogos entre poderes como forma não apenas possível de convivência entre eles, mas também de melhor efetivação de direitos sociais constitucionais, como é o direito à saúde, poderemos então passar a analisar instrumentos de diálogos interinstitucionais no interior das decisões judiciais, com exemplos práticos adotados pelo Poder Judiciário no Estado do Ceará, como veremos.

\section{OS DIÁLOGOS NO INTERIOR DAS DECISÕES JUDICIAIS: A EXPE- RIÊNCIA DO NAT - JUS}

Ainda segundo destaca Jorge Munhós de Souza, no ramo prescritivo das teorias dialogais, incidente quando elas são adotadas no interior das decisões judiciais, não deve haver uma concorrência sobre quem dará a última palavra, mas um diálogo permanente entre as instituições, cujos conhecimentos singulares técnicos e decisórios são parceiros na busca do melhor significado constitucional, cujo objetivo final seria encontrar boas respostas para questões coletivas ${ }^{38}$. Conrado Hübner indica que, nos casos dos diálogos observados no interior das decisões judiciais, não se restringem ao binômico constitucional e inconstitucional, independente do grau que a decisão judicial tenha, seja mais deferente, passiva e minimalista, como os modelos de diálogos de Bickel e de Sustein, nos quais a deliberação entre os poderes e a sociedade será meIhor quanto menos a corte se intrometer; ou mais intervencionista, ativa e maximalista,

\footnotetext{
35 SOUZA, Jorge Munhós de. Diálogo institucional e direito à saúde. Salvador: JusPodvim; 2013. p. 74.

36 SOUZA, Jorge Munhós de. Diálogo institucional e direito à saúde. Salvador: JusPodvim; 2013. p. 100.

37 SOUZA, Jorge Munhós de. Diálogo institucional e direito à saúde. Salvador: JusPodvim; 2013. p.103-104, 112.

38 SOUZA, Jorge Munhós de. Diálogo institucional e direito à saúde. Salvador: JusPodvim; 2013. p. 75-76.
} 
como o modelo de dialogal de Katyal, para o qual o diálogo não será melhor se a corte ficar em silêncio, mas se fizer recomendações, cogitações, argumentação hipotética e analógica, de natureza não-vinculante 39 .

No que se refere à possibilidade de aplicação desse ânimo dialógico quanto às decisões judiciais em questões sanitárias, além das já citadas limitações de análise das escolhas econômica e social (na Seção 02), as decisões judiciais não podem se furtar ao fato de não serem tecnicamente hábeis a fazer uma análise médica ou farmacêutica. Desse modo, outro argumento para a necessidade de diálogos entre as instituições e atores envolvidos na efetivação de direitos sociais, especialmente do direito à saúde, decorre do fato de o membro do Poder Judiciário não ser autoridade em todas em as ciências, especialmente quando se fala em tutela do direito à saúde, nas ciências médica, política, orçamentária e econômica, mas é autoridade quando se fala no poder de decidir pelo Direito. Ocorre que nem sempre as questões podem ser entendidas apenas pelo enfoque jurídico. A garantia de direitos como às ações de promoção e recuperação da saúde não se esgotam em tarefas puramente jurídicas, como ressalta Daniel Sarmento, sempre envolvem, na verdade, um conjunto de ações estatais, que compreendem a formulação de políticas públicas, a criação de procedimentos, o dispêndio de recursos, dentre outras atividades, que não são funções típicas do Judiciário40.

Exemplo do reconhecimento dessa necessidade dos atores jurídicos em buscar junto a profissionais técnicos da área da saúde auxílio nas soluções para questões de saúde levadas ao Poder Judiciário foi a implantação dos NAT-JUS (Núcleos de Apoio Técnico Judiciário para Demandas da Saúde) pelos Tribunais de Justiça e Tribunais Regionais Federais, com base na Resolução № 238 de 06/09/2016, do Conselho Nacional de Justiça41.Os NAT-JUS serão constituídos de profissionais da saúde, responsáveis pela elaboração de pareceres acerca da medicina baseada em evidências, servindo de prova pericial nessas demandas.

Embora a referida resolução tenha sistematizado o funcionamento dos NATJUS nos Tribunais de Justiça, a medida já era estimulada pelo CNJ pelo menos desde 2014. Os Enunciados da I Jornada de Direito da Saúde do Conselho Nacional de Justiça42, aprovados em 15/05/2014, sugeriam aos juízes que utilizassem a ferramenta de

\footnotetext{
39 HÜBNER, Conrado Mendes. Direitos fundamentais, separação de podores e deliberação. São Paulo, 2008. 224 f. Tese (Doutorado) - Departamento de Ciência Política da Faculdade de Filosofia, Letras e Ciências Humanas da Universidade de São Paulo. p. 100, 123.

40 SARMENTO, Daniel. Por um constitucionalismo Inclusivo: História Constitucional Brasileira, Teoria da Constituição e Direitos Fundamentais. Rio de Janeiro: Lume Juris, 2010. p. 191.

41 BRASIL. CONSELHO NACIONAL DE JUSTIÇA. Resolução nº 238 de 06/09/2016. Disponível em: <http://www.cnj.jus.br/busca -atos-adm?documento=3191>. Acesso em: 22 jun. 2017.

42 ENUNCIADO N. 18: Sempre que possível, as decisões liminares sobre saúde devem ser precedidas de notas de evidência científica emitidas por Núcleos de Apoio Técnico em Saúde -NATS. ENUNCIADO N. ${ }^{\circ}$ 31: Recomenda-se ao Juiz a obtenção de informações do Núcleo de Apoio Técnico ou Câmara Técnica e, na sua ausência, de outros serviços de atendimento especializado, tais como instituições universitárias, associações profissionais, etc.
} 
consulta aos Núcleo de Apoio Técnico (NAT) ou Câmara Técnica. Assim, após a distribuição da ação judicial, o magistrado encaminharia cópia da petição inicial e dos documentos ao Núcleo de Apoio Técnico (NAT) ou Câmara Técnica que se manifesta sobre a matéria, prestando informações que auxiliam o juiz na análise do pedido de liminar ou do pedido de mérito. A análise poderia se dar, por exemplo, se: (1) o medicamento postulado está registrado na Anvisa; (2) é eficaz e eficiente ao tratamento da doença; (3) existe outro medicamento com menor preço, com o mesmo princípio ativo, ou já fornecido administrativamente pelo SUS; (4) eficiência, eficácia e custo-efetividade do tratamento. Essa iniciativa fomentou a criação de órgãos compostos por profissionais da área médica, farmacêutica, assistência social e por membros das Secretarias Estaduais e Municipais de Saúde que tem por finalidade auxiliar os magistrados na deliberação sobre processos envolvendo temas de saúde 43 .

No Estado do Ceará, por exemplo, o Tribunal de Justiça firmou, em 11 de novembro de 2016, Termo de Cooperação Técnica com o Estado do Ceará e o Município de Fortaleza, por meio das respectivas Secretarias de Saúde, e ainda com o Hospital Universitário Walter Cantídio, da Universidade Federal do Ceará (UFC), administrado pela Empresa Brasileira de Serviços Hospitalares - EBSERH, para a produção de documentos técnicos, subdivididos em pareceres ou notas técnicas, por uma Câmara Técnica, formada por médicos e farmacêuticos do quadro de servidores do Estado, Município e Hospital Universitário, que auxiliarão os magistrados na formação de um juízo de valor por ocasião da apreciação das questões clínicas apresentadas nas ações judiciais envolvendo a assistência à saúde pública, especificamente as relacionadas com pedidos de medicamentos. O magistrado encaminha as demandas à Câmara Técnica por e-mail, fornecendo as informações necessárias ao atendimento da demanda. As respostas técnicas rápidas e as notas técnicas serão produzidas em até cinco dias úteis, sendo as primeiras utilizadas nos casos em que não seja necessário levantamento bibliográfico complexo, e as últimas para casos específicos que demandem revisão bibliográfica e análises de custo, riscos e benefícios dos tratamentos 44 .

Como a medida foi implantada recentemente, a portaria que disciplinou o funcionamento do NAT-JUS no Tribunal de Justiça do Estado do Ceará (TJCE) foi publicada em 08 de setembro último45. Segundo pesquisas realizadas junto à Secretaria Executiva do Comitê Executivo da Saúde no Ceará, até a conclusão deste trabalho, foram realizadas 58 consultas, com solicitação de parecer, no âmbito da Justiça Estadual do Ceará. Dessas solicitações, já foram produzidos 49 pareceres pelo NAT-JUS, no formato

\footnotetext{
43 SCHULZE, Clenio Jair. O papel do Conselho Nacional de Justiça na judicialização da saúde. Brasília: Conselho Nacional de Secretários de Saúde - CONASS, 2015. p. 06.

44 Disponível em: <http://www.tjce.jus.br/wp-content/uploads/2017/08/FORMA-DE-CONSULTA-final-cut-PDF.pdf> Acessado em 11 out. 2017.

45 Disponível em: <http://www.tjce.jus.br/wp-content/uploads/2017/10/Portaria-1536-2017.pdf>. Acessado em 11 out. 2017.
} 
de notas técnicas, todas disponibilizadas no site do TJCE46, para consulta pública, preservados os detalhes do caso, inclusive o nome dos pacientes.

Por enquanto, somente magistrados das Varas da Fazenda Pública e dos Juizados Especiais da capital do Estado é que podem solicitar demandas ao NAT-JUS, mas, segundo informações coletadas no Comitê Executivo da Saúde no Ceará, há interesse por parte do Tribunal de Justiça e dos próprios magistrados do interior do Estado na ampliação de atendimentos, o que depende, contudo, da cessão de mais profissionais da saúde pelos demais entes integrantes do termo de cooperação técnica. Contudo, com a disponibilização na Internet dos pareceres já produzidos pelo NAT-JUS, em casos semelhantes aos já submetidos à Câmara Técnica, pode-se utilizar as informações já disponíveis nos pareceres elaborados.

Apurou-se ainda que, até o momento, grande parte das solicitações dos magistrados diz respeito a medicamentos e insumos e/ou equipamentos (bomba de insulina, por exemplo). Outras demandas não entraram na cooperação técnica em virtude de especificidades que não as compatibilizam com o funcionamento dessa ferramenta de diálogo. Por exemplo, conforma apurado, a necessidade de leitos de UTI não se enquadra nas hipóteses de atendimento do NAT-JUS, uma vez que o magistrado, nesses casos, decide imediatamente, não podendo aguardar o prazo de cinco dias úteis necessários para a elaboração do parecer técnico.

Ainda com base em informações colhidas para a presente pesquisa junto ao Comitê Executivo da Saúde no Ceará, há um termo de cooperação entre o TJCE e o Município de Fortaleza, através da Central Integrada de Leitos, para que os juízes possam solicitar informações sobre a fila de espera de leitos de UTI de forma mais ágil, cuja implementação se encontra em trâmite.

Apresentados esses dados acerca das práticas dialogais levadas a efeito pelo Tribunal de Justiça do Ceará, cabe informar que no âmbito do Ministério Público há iniciativas semelhantes para atuações extrajudiciais, como o NAT-PRÉ - Núcleo de Apoio Técnico no Pré Processo do Ministério Público de Minas Gerais 47 e o NAT - Núcleo de Apoio Técnico do Ministério Público do Estado do Ceará. O NAT-PRÉ se parece mais com o proposto no Poder Judiciário (NAT-JUS), restringindo aos feitos de saúde.

Quando se visualizam exemplos práticos que se referem ao uso dos diálogos institucionais em matérias atinentes à concretização do direito à saúde, vê-se que as questões podem ir além da mera discussão acerca da legitimidade ou não de intervenção do Poder Judiciário em matérias que a rigor deveriam ser discutidas na órbita de outras instituições. Jorge Munhós de Souza acredita que o uso das teorias do diálogo institucional não firma oposição ao controle judicial ou ainda desconsideram a importante

\footnotetext{
46 Disponível em: <http://www.tjce.jus.br/nota-tecnica/ >. Acessado em 24 out. 2017.

47 Disponível em: <https://www.mpmg.mp.br/files/diariooficial/DO-20170127.PDF>. Acesso em: 02 jul. 2017.
} 
função do Judiciário na construção de um País mais justo. As teorias do diálogo vão de encontro a uma supremacia judicial absoluta e irrestrita em suas decisões, sufocandose os demais espaços de decisões coletivas da comunidade política, que nega limitações cognitivas e a possibilidade de efeitos sistêmicos adversos decorrentes de suas decisões, acreditando que um controle judicial mais fraco poderá melhor contribuir48.

A disseminação da cultura de diálogo pode contaminar diversas decisões judiciais mais próximas. Como destaca Conrado Hübner Mendes ${ }^{49}$, o diálogo nasce da conjugação de um desenho institucional e de uma cultura política, criando-se incentivos para a interação em variadas formas 50 .

Desse modo, a solução mais conciliatória, não imposta pelo Poder Judiciário, mas construída com o auxílio técnico em saúde, orçamento e gestão de profissionais do Poder Executivo, interessa à demonstração da atuação coordenada como meio mais eficaz da efetivação do direito à saúde. Ademais, pensar o Sistema Único de Saúde (SUS) sob uma perspectiva de diálogo entre agentes da promoção da Justiça e agentes de promoção da saúde (gestores públicos, sobretudo do Poder Executivo, e profissionais da área de saúde), incluindo na participação do diálogo a sociedade civil, faz com que o SUS dê certo, uma vez que as soluções alcançadas nesse modelo de construção nos permitem concluir que a forma como o sistema foi idealizado é viável, diante do seu fortalecimento para esta e para as futuras gerações de usuários do sistema.

\section{CONCLUSÕES}

Diante do atual quadro de prestações dadas pelo Poder Judiciário em matéria de direitos sociais e dos correspondentes questionamentos lógicos em face da separação dos poderes, apresentou-se, neste trabalho, fatores estimulantes de uma atuação cooperativa e complementar entre os atores estatais para realizar os fins almejados na Constituição, tais como: uma separação dinâmica entre os poderes, com fluidos mais colaborativos; um reconhecimento pelos atores jurídicos de suas limitações técnicas (especialmente no que se refere aos aspectos de gestão pública e de orçamento, bem como médicos e farmacêuticos), abrindo-se para uma fase de colaboração nas políticas públicas e não mera criação das mesmas por meio de decisões judiciais, ainda que coletivas; além de uma maior consciência dos efeitos de uma decisão judicial para

\footnotetext{
48 SOUZA, Jorge Munhós de. Diálogo institucional e direito à saúde. Salvador: JusPodvim; 2013. p. 118-119.

49 Embora esse autor não aborde a participação do Poder Executivo nos diálogos, apenas do Judiciário e do Legislativo, justificando sua opção no fato de estar nesses dois últimos poderes a pecha de detentores da última palavra, ideia que busca desconstruir o autor ao longo de seu trabalho, para as compreensões do presente estudo, a participação do Executivo no ciclo de diálogos revela-se de suma importância, inclusive porque quando se trata de direito à saúde, emana desse Poder a grande gama de atos normativos, como portarias, resoluções etc, além dos atos executivos que põem o Sistema público de Saúde em prática.

50 HÜBNER, Conrado Mendes. Direitos fundamentais, separação de podores e deliberação. São Paulo, 2008. 224 f. Tese (Doutorado) - Departamento de Ciência Política da Faculdade de Filosofia, Letras e Ciências Humanas da Universidade de São Paulo. p. 159.
} 
o Sistema público de saúde como um todo. Uma atuação articulada no exercício das atribuições de definir, executar e fiscalizar as políticas públicas passa a ser uma solução viável e balizada no ordenamento jurídico brasileiro.

Partindo da premissa dos interesses confluentes na realização do direito à saúde, esboçou-se que mesmo o controle de políticas públicas realizado fora das instituições onde elas são idealizadas, ou seja, aquele realizado pelo Poder Judiciário, Ministério Público e Defensoria Pública, deve ocorrer com base em diálogos entre as instituições políticas e jurídicas, bem como mediados sempre no conhecimento amplo das questões que envolvem as lides a respeito dos direitos sociais, especialmente nas áreas técnicas de saúde, orçamentária, financeira, de gestão, política e jurídica. Esses fatores articulados constroem a proteção adequada ao direito à saúde e sinalizam uma luz diante dos problemas que envolvem o controle judicial de políticas públicas.

Visualizar as demandas de saúde sobre esse prisma permite que os atores jurídicos contribuam para o planejamento das políticas públicas de saúde em maior medida que quando simplesmente impõem condutas que julguem adequadas, ao alvedrio dos planos e programas de saúde já instituídos. Tal se verifica nos projetos de NAT-JUS em que o Poder Judiciário se apresenta mais como colaborador na execução de políticas públicas de saúde que como impositor de soluções unilateralmente construídas, por meio da ferramenta de consulta técnica mais próxima do magistrado, estimulando-o a não proferir decisões em face do Poder Público, na seara de demandas que envolvem o direito à saúde, sem consultar os profissionais do próprio Sistema Único de Saúde de maneira rápida e confiável. Esse parece ser o grande diferencial dessa proposta de câmaras ou núcleos técnicos incentivados pelo Conselho Nacional de Justiça e aplicados pelos Tribunais de Justiça e Tribunais Regionais Federais em todo o País: ampliar a segurança dos magistrados em suas decisões, notadamente as liminares, sem as demoras que um modelo menos instrumental e dialogal ocasionam nos esclarecimentos prestados pelos Entes públicos quanto às demandas que se encontram no Poder Judiciário.

A experiência no Tribunal de Justiça do Ceará tem se demonstrado exitosa, por sua vez, tanto do ponto de vista do processo judicial específico em que o parecer técnico é proferido, tendo pleno potencial de auxiliar na resolução da demanda, quanto da perspectiva de disseminação de informação técnica que os pareceres apresentam ao Poder Judiciário, construindo o diálogo institucional necessário e salutar aos desafios presentes na execução das políticas públicas de saúde.

Superar os debates em torno da possibilidade ou não de prestações judiciais que modifiquem o funcionamento do sistema de saúde diante de omissões na prestação de serviços públicos de saúde, por meio de ferramentas fornecidas ao magistrado pelos profissionais que estão na ponta da cadeia de prestação de saúde pública, além de ser uma solução viável, como demonstra a iniciativa no Tribunal de Justiça do Estado do Ceará, possibilita a ampliação da cultura do diálogo entre os poderes, abrindo 
portas para outras espécies de participação e cooperação, inclusive, para além das demandas de saúde.

\section{REFERÊNCIAS}

BATEUP, Christine. The dialogic promise: assessing the normative potential of theories of constitutional dialogue. New York: New York University School of Law, 2005.

BRASIL. Constituição (1988). Constituição da República Federativa do Brasil, Brasília, DF, Senado, 1988.

BRASIL. Lei Federal n 8.080/90, Lei Orgânica Nacional da Saúde. Dispõe sobre as condições para a promoção, proteção e recuperação da saúde, a organização e o funcionamento dos serviços correspondentes e dá outras providências.

BRASIL. CONSELHO NACIONAL DE JUSTIÇA. Resolução no 238 de 06/09/2016. Disponível em: <http://www.cnj.jus.br/busca-atos-adm?documento=3191>. Acesso em: 22 jun. 2017.

BUCCI, Maria Paula Dallari. As políticas públicas e o direito administrativo. Revista de informação legislativa, Brasília, v. 34, n. 133, p. 89-98, jan./mar. 1997.

CEARÁ. TRIBUNAL DE JUSTIÇA DO ESTADO DO CEARÁ. (Ed.). Diário Oficial Eletrônico do Tribunal de Justiça do Estado do Ceará de 08/09/2017. Disponível em: <http://www.tjce.jus.br/wpcontent/uploads/2017/10/Portaria-1536-2017.pdf>. Acessado em 11 out. 2017.

GABARDO, Emerson. Princípio Constitucional da Eficiência Administrativa. São Paulo: Dialética, 2002.

GRIMM, Dieter. Constituição e Política. Tradução Geraldo de Carvalho. Belo Horizonte: Del Rey, 2006.

HACHEM, Daniel Wunder. A maximização dos direitos fundamentais econômicos e sociais pela via administrativa e a promoção do desenvolvimento. Revista de Direitos Fundamentais e Democracia, Curitiba, v. 13, n. 13, p. 340-399, jan./jun. 2013.

HÜBNER, Conrado Mendes. Direitos fundamentais, separação de poderes e deliberação. São Paulo, 2008. 224 f. Tese (Doutorado) - Departamento de Ciência Política da Faculdade de Filosofia, Letras e Ciências Humanas da Universidade de São Paulo.

KRELL, Andreas J. Direitos sociais e controle judicial no Brasil e na Alemanha: os (des)caminhos de um direito constitucional comparado. Porto Alegre: Fabris, 2002.

MARIANO, Cynara Monteiro; LIMA, Martonio Mont'Alverne Barreto; ALBUQUERQUE, Newton Menezes. Serviços públicos e radicalização do Estado Social: o lugar para uma perspectiva socialista nos dias atuais? In: MARIANO, Cynara Monteiro et all (Org.). Estado, Política e Direito Administrativo. Rio de Janeiro: Lumen Juris, 2017. 
MATIAS, João Luis Nogueira; MUNIZ, Águeda. O poder judiciário e a efetivação do direito à saúde. Revista Brasileira de Políticas Públicas, Brasília, v. 5, n. 1, p. 194-206, 2015.

MENICUCCI, Telma Maria Gonçalves. Público e privado na política de assistência à saúde no Brasil: atores, processos e trajetória. Rio de Janeiro: Editora FIOCRUZ, 2007. 320 p. Disponível em <http://books.scielo.org>. Acessado em 21 abr. 2017

MINAS GERAIS. MINISTÉRIO PÚBLICO DO ESTADO DE MINAS GERAIS. (Ed.). Diário Oficial Eletrônico do Ministério Público de Minas Gerais de 27/01/2017. 2017. Disponível em: <https://www. mpmg.mp.br/files/diariooficial/DO-20170127.PDF>. Acesso em: 02 jul. 2017.

NEVES, Marcelo. A Constitucionalização Simbólica. São Paulo: WMF Martins Fontes, 2007.

PROCURADORIA-GERAL DE JUSTIÇA DE MINAS GERAIS. Saúde Compartilhada: MPMG se une a órgãos e instituições em busca de alternativas aos problemas de saúde no estado. Informativo da Procuradoria-geral de Justiça de Minas Gerais. Belo Horizonte, p. 02-02. 07 ago. 2013. Disponível em: <https://goo.gl/78826X>. Acesso em: 25 jun. 2017.

RABELLO, Lucíola Santos. Promoção da saúde: a construção social de um conceito em perspectiva do SUS. Rio de Janeiro: Editora FIOCRUZ, 2010.

SARMENTO, Daniel. Por um constitucionalismo Inclusivo: História Constitucional Brasileira, Teoria da Constituição e Direitos Fundamentais. Rio de Janeiro: Lume Juris, 2010.

SCHULZE, Clenio Jair. O papel do Conselho Nacional de Justiça na judicialização da saúde. Brasília: Conselho Nacional de Secretários de Saúde - CONASS, 2015.

SOUZA, Celina. Estado da arte da pesquisa em políticas públicas. In: HOCHMAN, G.; ARRETCHE, M.; MARQUES, E. (Orgs.). Políticas públicas no Brasil. Rio de Janeiro: Editora FIOCRUZ, 2007.

SOUZA, Jorge Munhós de. Diálogo institucional e direito à saúde. Salvador: JusPodvim; 2013. TORRES, Heleno Taveira. Direito constitucional financeiro. São Paulo: Thomson Reuters; Revista dos Tribunais, 2014.

TUSHNET, Mark. Alternative Forms of Judicial Review. Michigan Law Review, Ann Arbor, vol. 101, n. 8, aug. 2003.

VALLE, Vanice Regina Lírio do. Dialogical constitutionalism manifestations in the Brazilian judicial review. Revista de Investigações Constitucionais, Curitiba, vol. 1, n. 3, p. 59-90, set./dez. 2014.

VALLE, Vanice Regina Lírio do. Diálogo institucional com pressuposto da efetividade constitucional. A\&C. Revista de Direito Administrativo e Constitucional, Belo Horizonte, n. 23, ano 6, jan./ mar. p. 189-206, jan./mar. 2006. 